\title{
SIMPLICITY IN THE COMPLEXITY OF ORGANIZING THE OLYMPIC GAMES: THE ROLE OF BUREAUCRACY
}

\author{
DIMITRIS GARGALIANOS, * MAKIS ASIMAKOPOULOS, $\dagger$ \\ PACKIANATHAN CHELLADURAI, $\ddagger$ AND KRISTINE TOOHEY§ \\ *Department of Physical Education \& Sport Science, Democritos University of Thrace, Komotini, Greece \\ †Synergy Sports, Athens, Greece \\ $\ddagger$ Department of Kinesiology and Health Promotion, College of Health and Human Services, \\ Troy University, Troy, AL, USA \\ §Department of Tourism and Sport, Griffith University, Gold Coast, QLD, Australia
}

\begin{abstract}
The Olympic Games involve many individual and organizational stakeholders as well as an infinite number of tasks requiring technical competence; hence, they are complex to organize. On the other hand, there are constant principles in their organization that are determined by the rules of the 2014 Olympic Charter and the Host City Contract (HCC), which affect the Organizing Committee of the Olympic Games (OCOG), an entity of limited duration established with a single mandate: to organize the Games. The purpose of this study was to investigate whether the organizational efforts of an OCOG are guided by Weber's tenets of bureaucracy: division of labor; authority structure; system of abstract rules; impersonality; and technical competence. In order to fulfill this purpose the authors used a case study methodology and investigated the Athens 2004 Organizing Committee of Olympic Games (ATHOC). The methodology also included review of relevant literature and official ATHOC documents, especially the 2004 Official Post Games Report. Moreover, personal experience of the first and second authors, who were contractually involved with the organization of the Athens 2004 Olympic Games, was employed. It was concluded that ATHOC used Weber's tenets of bureaucracy to simplify its organizational efforts.
\end{abstract}

Key words: Olympic Games (OG); Simplicity; Weber’s tenets of bureaucracy

Introduction

Mega-sports events, such as the Olympic Games (OG), garner global media attention and interest among the public. The complexity associated with organizing and conducting such an event has been well documented in mass media and also in scholarly documents. For example, the enormity and complexity of organizing an OG was described through a comprehensive three-dimensional 
schematic representation of the stakeholders involved (Gargalianos, Stotlar, \& Toohey, 2012).

From the practitioner's viewpoint, Asimakopoulos (2006), General Manager sports for the Athens 2004 Organizing Committee of Olympic Games (ATHOC), outlined the elements that contributed to the complexity of organizing the Athens Games (Chelladurai, 2014). In the Athens 2004 OG, 202 National Olympic Committees (NOCs) registered 10,862 athletes and 5,501 team officials, who participated in events in 28 sports (ATHOC, 2005a, p. 361). Each sport was organized and supervised by the corresponding 28 international federations (IFs) (International Olympic Committee, 2014), which worked closely with their Hellenic counterparts. The organizers of the Games had to plan, organize, and coordinate an infinite number of tasks that had to be performed by all stakeholders in a way that ticketed and television spectators would not realize the extent of the Games' organizational complexity. For example, for the track and field hurdle events, a specific number of hurdles of appropriate specifications had to be sourced, stored, placed in the right places on the track at the right times, removed promptly after the races were over to make room for the next track events, stored after the event, and finally disposed of after the Games. Spectators simply expected that the hurdles were there at race time.

There is an extraordinary amount of time and individual/collective effort spent on Olympic planning in all functional areas (FAs), across all sports, and in all competition/training/support venues. The planning for an OG begins many years in advance by the host city's Bid Committee and intensifies when the event is awarded, 7 years before its actual delivery. From this point on, in order to be effective and efficient, Organizing Committees of Olympic Games (OCOG) have to follow certain simple imperatives.

\section{Purpose of the Study}

The purpose of this study was to investigate whether the organizational efforts of an OCOG follow Weber's (1947) tenets of bureaucracy: division of labor; authority structure; system of abstract rules; impersonality; and technical competence.

\section{Review of Literature}

Organizations and theories explaining their behavior have been the object of scholars' interest for many decades. For example, classical organization theory evolved during the first half of the 20th century and was a merger of scientific management, bureaucratic theory, and administrative theory. Its first well-known advocate was Frederick Taylor (1919), whose theory suggested four basic principles of management: a) find the best way to perform each task, b) match each worker to each task, c) closely supervise workers and motivate them with reward and punishment, and d) management's role is to plan and control.

Weber's (1947) seminal work expanded on Taylor's (1919) theories and stressed the need to reduce diversity and ambiguity in organizations. Although "bureaucracy" has often been used to describe large organizational structures or even as a pejorative term, Weber theorized bureaucracy as "an analytical concept, decoupled from the polemical context in which it had emerged" (Olsen, 2006, p. 2). Realizing that without any kind of bureaucracy an organization could be compared to a mob (Graetz \& Smith, 2006), Weber emphasized that large organizations needed a hierarchical structure of power, a division of labor, and specialization with a formal set of rules to ensure stability and uniformity (Walonick, 1993). This is known as bureaucratic theory and "connotes a set of theoretical ideas and hypotheses concerning the relations between organizational characteristics and administrative mentality, behavior, performance, and change" (Olsen, 2006, p. 3). Key features of Weber's ideal type of bureaucracy are a "division of labor, hierarchal order, written documents, well-trained staff and experts, full working capacity of the officials, and application of impersonal rules" (Hummel, 2007, p. 307). Weber's approach resonated with practitionersand "businessorganizationsincreasingly adopted Weber's principles of rational bureaucracy" (Ashforth \& Vaidyanath, 2002, p. 362). Al-Habil (2011) reports that, according to Weber, the ideal type of bureaucracy possesses rationally discussible grounds for every administrative act. This principle of rational decision making underpins bureaucracy.

Many sports governing bodies were developed in their modern organizational forms when Weber's 
(1947) ideas were gaining credibility with management as well as academia, and, as such, would be expected to follow his bureaucratic ideal type. Although peak sports organizations differed in the pace they adopted modern bureaucratic dimensions (Tomlinson \& Young, 2010), over time this adoption occurred and has been the focus of academic study. For example, previous work in sport and event literature has argued that voluntary sport organizations exhibit the characteristics of bureaucratic organizations (cf. Kikulis, Slack, Hinings, \& Zimmermann, 1989; Papadimitriou, 1994; Slack \& Hinings, 1994; Theodoraki, 1996; Thibault, Slack, \& Hinings, 1991). More specifically, in terms of theoretical applicability Frisby (1985), Slack (1985), and Theodoraki and Henry (1993) have suggested that the use of Weberian theory of bureaucracy is a relevant lens through which sport organizations can be studied as they demonstrate typical bureaucratic structures and processes (Papadimitriou, 2002).

\section{Methodology}

To test whether the principles of Weber's (1947) theory of bureaucracy underpins an OCOG's function, a single case study design was chosen. Although case studies, and specifically single, have been criticized for not producing generalizable results, generalizable findings are not the only valuable outcome of research (Yin, 2014). Flyvbjerg (2006), for example, promoted the value of concrete, context-dependent case knowledge in understanding management theory and practice and advocated that a "force of example" can be an alternative to generalization. Further, a case study is an appropriate research approach when current knowledge of a phenomenon is "shallow, fragmentary, incomplete, or nonexistent” (Punch, 2005, p. 147). This was the case here as our review of literature had identified only limited empirical research on this area in the general sport event management literature and even less regarding the $\mathrm{OG}$.

The research methods used to investigate the specific case of Athens 2004 were qualitative because such methods for collecting and analyzing data in case study research facilitate an in-depth exploration of the case through examining its context and the perspectives of key individuals and groups involved (Gillham, 2000). In terms of the research tools a document analysis was conducted and participant observation of the organization of the Athens 2004 OG by the first and second authors, who were contractually engaged with ATHOC, was also utilized. The document search included a combination of primary sources, including official ATHOC documents, especially the Official Report of the XXVIII Olympiad.

The relevance of using documentary evidence in qualitative research has been documented by many authors (cf. Jupp, 2006; Punch, 2005). More specifically, document analysis is acknowledged to be appropriate in case study research, as documents "are a rich source of data for social research" (Punch, 1998, p. 190). In this study they provided a valuable source of primary data. The document analysis also allowed for crystallization of data obtained through the participant observations.

The document analysis was undertaken using five a priori codes based on Weber's tenets of bureaucracy. These codes were: division of labor; authority structure; system of abstract rules; impersonality; and technical competence. Two of the authors coded the material independently and cross-checked their results at regular intervals to reduce individual bias.

It is acknowledged that there are limitations to this approach, just as there are for all research; however, document analysis is a powerful data reduction technique. Its major benefit comes from the fact that it is a systematic, replicable technique for compressing many words of text into fewer content categories based on explicit rules of coding. It is relatively unobtrusive and useful in dealing with large volumes of data (Stemler, 2001). This approach was considered appropriate for this exploratory case study to provide insight into a previously unresearched topic.

\section{Results and Discussion}

The results on Weber's (1947) five a priori codes used in his theory of bureaucracy are presented and discussed below.

\section{Division of Labor}

Weber's first tenet of a bureaucracy relates to how an organizational labor is structured. Organizational 
structuring is defined as the sum total of the ways in which an organization divides and coordinates its labor into distinct tasks (Mintzberg, 1979). ATHOC started organizing the Games with people who worked for the Bid Committee. When the event was awarded to Athens their number grew in time and they were divided into smaller units to serve certain purposes. The institutional division of labor actually started by establishing the following Committees early in the lifecycle of the organization:

- The "Athens 2004 Organizing Committee for the Olympic Games," which was a private law corporate body established pursuant to Greek Law 2598/1998, Article 2 (Greek Government Gazette, 1998), and in accordance with Article 6 of the Host City Contract (HCC) (ATHOC, 2005a, pp. 88-92). It was established to plan and deliver all operations/services directly and indirectly related to the organization of the Games through the FAs (i.e., sport, accommodation, transportation, technology, etc.), to the various groups, called “clients/constituency groups” (i.e., athletes, NOCs, VIPs, media, sponsors, TV rights holders, spectators, etc.), at the proper places called "venues" (i.e., competition/training/ supporting venues, accommodation sites, transportation centers, etc.).

- The "National Committee for the Olympic GamesAthens 2004” (Greek Government Gazette 1998), which: a) involved political, social, intellectual, artistic, and sports personalities of the country, b) was established to provide proper and uniform political guidance and advice to the Organizing Committee, and c) was placed under the auspices of the President of the Hellenic Republic.

- The "Inter-Ministerial Committee for the Coordination of the Olympic Preparation" (Greek Government Gazette, 2000) provided the ultimate decision-making authority regarding all important matters related to the nationwide preparation of the Games. It was headed by the Prime Minister of the Government and coordinated the preparation/ delivery of: a) all infrastructures directly or indirectly related to the Games (i.e., sport facilities, roads, accommodation sites, etc.), and b) all services that were necessary for the Games and had to be provided by Ministries and State agencies (i.e., customs, telecommunications, etc.) according to the contractual agreements with the IOC and the technical guidance provided by ATHOC experts. In order to establish clear bilateral communication channels and have immediate information on ATHOC progress all Ministries and State Agencies involved with the Games appointed one liaison person with ATHOC.

Coordinating mechanisms were formalized at an interministerial level with the institution of the "Interministerial Committee for Coordination of Olympic Preparation" (DESOP) and the "Project Management Team” (ODE) (ATHOC, 2005a, p. 166). Both bodies were oriented towards a macrocoordination at top executive level and not towards the day-to-day issues (i.e., legal appeals, lawsuits, land expropriation, evictions, local demands, etc.) that required practical, prompt, and coordinated solutions.

In order for daily supervision to be exercised and all issues related to the progress of Olympic Works resolved, the "Project Monitoring Group" (OPE) was established. OPE was a small and flexible mechanism with tripartite representation (Ministry of Culture/Ministry of Environment \& Public Works/ATHOC), with the support of the General Secretary for the OG and with the participation of the Technical Advisor to the Prime Minister. Being the forum to which all parties resorted for the resolution of issues concerning the preparation of the Venues and related infrastructure, OPE's contribution was positively decisive for the timely completion of the Olympic Works because it eliminated cumbersome and time-consuming bureaucratic procedures (ATHOC, 2005a, p. 167).

Throughout the preparation period and according to the needs of each different phase ATHOC divided its work into:

1. Services required by the "clients/constituency groups" of the Games, which were delivered at each venue in a uniform way (i.e., IOC services, medical services, food services, etc.).

2. Venues, which were distinguished in competition, training, and support and they were run by a uniform venue management system.

3. Programs, which were usually one-off events (i.e., promotional events, press conferences, PR activities, etc.), one-venue events (i.e., Opening 
and Closing Ceremonies, etc.), or multivenue events (i.e., Torch Relay, etc.).

4. Coordination Areas/Units of the Games, which were necessary for the integration of the Games operations and the coordinated development of uniformed policies and procedures of the event (i.e., games planning, test events, etc.).

According to the above parameters, ATHOC was divided into the following major divisions, consisted of departments (FAs), which were also divided into smaller sections of related projects.

- Sport: It was responsible for the: a) planning and implementation of all Olympic and Paralympic sports technical requirements [in close collaboration with and under the direction of the IFs (and their national counterparts), which according to the Olympic Charter are responsible for the technical control and management of their sport at the Games - the FA was the designated single point of contact with the IFs for all matters related to policy and level of service concerning members of the IFs, the athletes, and the Technical Officials], b) development of the competition schedule, c) development and management of the Games training schedules, d) development of the Pre-Games Training Guide, e) eligibility and qualification control of athletes (sport entries), f) determination, in collaboration with the IFs, of the number of Technical Officials per sport and the securing of the necessary number of National Technical Officials, g) drafting, in cooperation with the IFs, of the field of play and the training sites' technical requirements, h) coordination of the procedures for the certification of all fields of play and training sites by the relevant IFs, i) production of sports technical publications and forms (e.g., Athletes' Entry and Eligibility Conditions Forms, etc.), related guides (e.g., Athletes' Guide), and manuals (e.g., Athletes' Sports Entries and Qualification Manual), j) participation in the Olympic Results \& Information Services (ORIS) program for the specification of system requirements for the timing \& scoring and games results, $\mathrm{k}$ ) training of volunteers in specialized tasks of competition management, and l) collaboration with the appropriate agencies for securing specialized Games Meteorological Support Services (ATHOC, 2005a, p. 361).
- Administration-Finance: Included the Office and Building Administration, Legal Services, Brand Protection, Financial Services, Procurement, Logistics, Rate Card, and Risk Management FAs (ATHOC, 2005a, p. 117).

- Marketing: In order to obtain funds for the successful organization of the Games, and in order to satisfy the need for specific products/ services required for that task, ATHOC sought and achieved collaborations with commercial entities active in various areas (beyond the International TOP Sponsors contracted by the IOC) to operate as National Sponsors, contributing financial resources and/or products/services for the Games (ATHOC, 2005a, p. 136).

- Security: This function was entrusted by law to the Olympic Games Security Division, a special autonomous service established under the direct jurisdiction of the Chief of the Hellenic Police, which: a) planed the law enforcement, security, and road traffic measures during the Olympic and Paralympic Games, b) supervised the operational implementation of the plans drafted, and c) coordinated all services and agencies involved in the security of the Games (ATHOC, 2005a, p. 187).

- Human Resources/Venue Staffing/Payroll: Responsible for: a) contributing to senior level strategic decision making concerning matters of human resource planning, budgeting, monitoring, and control, b) monitoring the application of company procedures and policies regarding paid staff, c) complying with relevant labor and insurance laws, d) drafting contracts, e) managing the paid staff, f) monitoring of working hour compliance, g) planning, developing, and monitoring operation of the human resources systems, and, through these, providing specialized support to the other FAs, h) disbursing remuneration and social security contributions for paid staff, and i) handling paid staff insurance matters (ATHOC, 2005a, p. 207).

- Volunteers: Identified the appropriate number of necessary volunteers, planned their recruitment procedure, organized the interviews, made the selection, managed their orientation training, and actively supported them during preparation/ operational phases for purposes of retention, welfare, and recognition of their contribution to the Games (ATHOC, 2005a, p. 211-212). 
- IOC Relations and Protocol: Responsible for the: a) determination and provision of services to the IOC and members of the Olympic Family in respect to their attendance in Athens up to and including the Games, b) coordination of all the Olympic Family members' visits to Athens, c) participation of ATHOC representatives in international meetings, d) submission of progress reports to the IOC, e) coordination of the delegations of ATHOC Observers to the 2000 Sydney and to the 2002 Salt Lake City Games, f) provision of a central coordination and information point for both internationally and locally hosted Olympic meetings, g) management, implementation, and observance of Olympic Protocol in the delivery of all services to the IOC and the Olympic Family, and h) support of other FAs with regard to issues of Protocol (ATHOC 2005a, p. 230).

- NOC Relations and Services: Provided NOCs with the necessary information and support to prepare the participation of their teams and delegations in the Games and maintained ATHOC image and values with all NOCs worldwide (ATHOC, 2005a, p. 235).

- Athens Olympic Broadcasting (AOB): Operated as an independent company and was responsible for the: a) production of the television and radio coverage of the Games, and $b$ ) provision to the Rights Holding Broadcasters of the facilities and services necessary for the broadcast of the Games (ATHOC, 2005, p. 253).

- Communications: Responsible for: a) defining, preparing, and implementing all ATHOC communications strategies and activities towards various target audiences, b) managing all operational campaigns pertaining to the Games, c) producing all ATHOC outreach to the public, media, and Olympic Family, and d) crisis communications (ATHOC, 2005a, p. 313).

- Information and Press Operations: Provided services to the domestic and international accredited members of the press in order to facilitate their work during the Games, which was to inform public opinion at home and abroad on all topics related to the Games (ATHOC, 2005a, p. 339).

- Technology: Supported ATHOC operations needing technology for their operations throughout the preparation period, as well as during Games time (ATHOC, 2005a, p. 393).
- Games Services: Included the accommodation, accreditation, transportation, food services, medical services and doping control FAs (ATHOC, 2005a, p. 417).

- Spectator Services: Operated as an independent company and ensured that all spectators: a) felt welcome, b) had all the necessary information and support while attending an Olympic event, and c) enjoyed both the sporting spectacle and the Greek hospitality (ATHOC, 2005a, p. 437).

- Venue Operations: Included the competition/ training/support venues, villages, overlays, site management, environment, energy, and cleaning and waste FAs.

- Programs: Included Opening/Closing Ceremonies of the Olympic and Paralympic Games, Cultural Program, Torch Relay, Medal Ceremonies, and Youth Camp FAs (ATHOC, 2005b, pp. 161, 459, 483, 511).

- Coordination Areas: It included the Games planning, test events, football tournament, paralympic games, transfer of olympic knowledge and the post games report FAs. Games planning determined the phases of the Games' organization as shown in Table 1 (Asimakopoulos, 2006).

Each FA developed and used modern management and information technology tools, systems, and databases for the: a) monitoring of progress in the implementation of Olympic Works, b) detailed planning and scheduling of all the activities that fell under ATHOC responsibility, and c) preparation of the relevant regular and special reports. The key tools included monthly and analytical progress reports, gap analysis (an issue monitoring system for

Table 1

Phases of the Games

\begin{tabular}{lcll}
\hline Phase & $\begin{array}{c}\text { Duration } \\
\text { in Years }\end{array}$ & Planning & \multicolumn{1}{c}{ Activities } \\
\hline 1 & 1 & General & $\begin{array}{l}\text { Identification of needs } \\
\text { Detailed plans for every FA } \\
2\end{array}$ \\
3 & 2 & $\begin{array}{l}\text { Analytical } \\
\text { Operational }\end{array}$ & $\begin{array}{l}\text { Integration of all detailed } \\
\text { plans into generic venue } \\
\text { operations plans }\end{array}$ \\
4 & 1 & Venuization & $\begin{array}{l}\text { Establishment of venue } \\
\text { teams + Refinement of } \\
\text { operational plans + Test } \\
\text { events }\end{array}$ \\
\hline
\end{tabular}


OPE), and the venue integrated timelines (ATHOC, 2005a, pp. 167-168).

Following Weber's (1947) view that bureaucratic organizations require well-trained staff and experts, each FA consisted of two kinds of managers: 1) Project Managers, who were professionals in charge of one Games-wide project of a specific FA, assigned with the responsibility to create, communicate, and enforce a set of uniformed plans, policies, and procedures regarding this project to all venues, sports, and programs. For example, in the sport FA there were the "sport equipment manager," the "technical officials services manager," the "results manager," etc.; in the transportation FA there were the "public transportation manager," the "VIP cars manager," the "parking lots manager," etc. 2) Venue FA Managers, who were professionals in charge of representing/operating all projects, of one FA, at one venue/sport/program of the Games. For example, the "cycling competition manager" coordinated all sport projects (i.e., sport equipment, results, etc.) at the cycling venue; the "Olympic Village Transportation Manager" coordinated all transport projects (i.e., public transport, VIP cars, etc.) in the Olympic Village, etc.

\section{Authority Structure}

Following Weber's (1947) second tenet that bureaucracies establish authority structures, ATHOC developed such structures as well. The Official Report of the XXVIII Olympiad contains six organizational charts (ATHOC, 2005a, pp. 104-115), underlining the fact that ATHOC authority structure considerably evolved in the preparation period according to operational necessities, and changed many times. During the most important phase of the Games, the delivery phase, the hierarchical authority structure consisted of a 17-member Board of Directors, a 5-member Steering Committee, the President, the Group General Managers, the General Managers, the Department (FA) Managers, the Competition Managers, the Venue Managers, the Project Managers, the Coordinators (of various tasks), and the Supervisors (of activities).

The 17-member Board of Directors was responsible for making all major strategic and budgetary decisions for the preparation and delivery of the Games. The members were appointed by the
Government (Minister of Culture) and most of them had no executive positions with ATHOC.

The 5-member Steering Committee was assigned the day-to-day executive decision making. Their weekly meetings secured lateral and vertical communication among the Executives, hence coordination and integration of the Games' work. The Committee was led by ATHOC's President and each of the other four Executive Directors (Group General Managers) was assigned with the leadership and coordination of one of the following major areas: 1) sport operations/games services, 2) company administration, 3) commercial affairs, and 4) Olympic works. For example, the Executive Director in charge of the sport operations/games services was responsible for the leadership and coordination of all General Managers related to the services (i.e., accommodation, transportation, medical services, etc.) required by and rendered to the major clients of the Games (i.e., sports, media, NOCs, Athens Olympic Broadcasting, etc.).

Each General Manager was assigned with the responsibility to lead and coordinate a number of departments (FAs) with a common purpose. At this level, divisional structures, weekly management meetings, and interdepartmental policies and procedures were established in order to secure proper communication and integration between Project Managers and FA Venue Managers. For example, in sport there were three departments (sport operations, sport services, and competition fields) with more than 35 sections, covering all aspects of the competition. All departments consisted of both Project and Competition Managers; Therefore, lateral communication was imposed at this level of the hierarchy not only by the policies and procedures of the division, but also by its authority structure.

\section{System of Abstract Rules}

The third of Weber's (1947) tenets is that bureaucracies should have a system of abstract rules. The basic set of rules that govern the Olympic Movement is the Olympic Charter, which has been updated many times in order to accommodate the needs of the Movement. The second most important set of rules that dictate the organization of OCOGs is the (quite extensive) Host City Contact and its appendixes, which is signed by the President of the 
IOC, the President of the NOC of the host country, and the Mayor of the host city, immediately after the announcement of the name of the city awarded with the privilege to host the Games. The HCC is then articulated into detailed guidelines for every function pertaining the planning and staging the Games. Based on the obligations derived from the HCC the country formulates laws regarding the organization of the Games, which are submitted to the Parliament to be voted for and published in the Government's Gazette. Moreover, there are the contracts that the IOC signs with certain entities (i.e., commercial companies, TV networks, etc.) providing them exclusive rights to the Games. All these sets of rules are very carefully prepared, involve many stakeholders, and are very hard and time consuming to change.

In order for the above described requirements to be materialized ATHOC established operations policies and procedures, which were influenced by the specific circumstances existing in the organization (i.e., leadership, politics, stakeholder involvement, available technology, venues, budget, etc.). In the initial phases of the Games' organization these policies and procedures are adjusted quite often to accommodate the growing organizational needs of the event, until they reach a point (a few months before the Games) that they are "locked in" and very difficult to change as well.

Moreover, following its establishment the OCOG organizes and enacts the cooperation and coordination framework with the public sector (i.e., Ministries), agencies from the broader public sector (i.e., hospitals), local authorities (i.e., Olympic Municipalities), and the private sector through Memoranda of Understanding (MoUs), which are drafted by special committees consisted of representatives of both parties and signed between the OCOG and the corresponding entity. The purpose of an $\mathrm{MoU}$ is to describe the areas of cooperation, based on the responsibilities of each entity and the OCOG Master Plan, always in accordance with contractual obligations undertaken towards the IOC and the IPC (ATHOC, 2005a, p. 275).

\section{Impersonality}

The fourth of Weber's (1947) bureaucratic tenets is impersonality. The Olympic Charter (2014) states that "any form of discrimination with regard to a country or a person on grounds of race, religion, politics, gender or otherwise is incompatible with belonging to the Olympic Movement" (Fundamental Principle 6, p. 12 ) [which, according to the Charter (page 15) consists of the IOC, the NOCs, the IFs, and the OCOGs]. Hence, all these organizations have to abide by this principle and work accordingly.

However, Fundamental Principle 6 is just the theory behind an inescapable reality. In order for a city to be awarded an edition of the Games it has to go through a rigorous process, which in most cases lasts for many years. A Bid Committee has to be established, the aim of which is to respond to all questions contained in the (quite extensive) Bid File issued by the IOC, not only in their "best possible way," but also in a way that it is superior to the file submitted by other Bid Committees. The only way a Bid Committee can do that is to employ people who have the appropriate knowledge, the experience, and a strong will to devote their time and energy to such a cause. Usually in the biding country there are many capable candidates from different political orientations who fulfill these criteria. So, in this phase, the decision about the persons who will lead the effort may become political. As soon as the leadership is appointed it is in the Committee's best interest to attract the most competent people in the market to assist them with the work necessary to be done for the configuration of an attractive Bid File, which will convince the IOC members to vote in their favor (Toohey \& Veal, 2007).

As soon as the Games is awarded to the city an OCOG is established. In the early stages the organization grows slowly, but in the course of the 7 years of preparation gradually transforms into a Fortune 500 company, delivers the Games, and dissolves immediately after. Table 2 presents the development of the Athens 2004 OCOG paid staff numbers (ATHOC, 2005a, p. 209).

\section{Technical Competence}

Weber's (1947) fifth tenet of bureaucracy is that the organization has technical competence. In the case of ATHOC, its entire staff was recruited by the ATHOC Human Resources Department through private sector procedures. In order to increase the possibility of hiring the most competent people ATHOC established the following basic recruitment 
Table 2

Athens 2004 OCOG Paid Staff Year by Year

\begin{tabular}{lcr}
\hline Month & Year & Paid Staff \\
\hline December & 1998 & 17 \\
December & 1999 & 96 \\
December & 2000 & 256 \\
December & 2001 & 661 \\
December & 2002 & 1,247 \\
December & 2003 & 2,108 \\
January & 2004 & 2,354 \\
March & 2004 & 2,923 \\
May & 2004 & 4,079 \\
June & 2004 & 5,393 \\
July & 2004 & 10,364 \\
August & 2004 & 13,710 \\
December & 2004 & 15 \\
January & 2005 & 0 \\
\hline
\end{tabular}

principles: a) full documentation of the necessity for recruitment, b) accurate description of the position/candidate's profile/level of knowledge/ selection criteria, c) objective selection procedure that guaranteed equal opportunities for everyone, including actual employees of ATHOC, who might be interested in applying for another position, and d) timely and accurate information provided to all candidates (ATHOC, 2005a, p. 206).

As an example, for the competition management of each sport, recruiting the best qualified professionals was a main priority. For the recruitment of people with the necessary technical aptitude and experience in each sport ATHOC cooperated closely with the Hellenic National Sports Federations (HNSF) and set and applied the following selection criteria: a) expert knowledge of each sport's technical rules and requirements, b) event organization experience, c) management experience, d) very good working knowledge of the English language, and e) computer skills (ATHOC, 2005a, p. 365). Figure 1 is the example of the public announcement of the Competition Manager Basketball position.

Further to the public announcement of positions, the sport competition managers were selected by a recruitment committee comprised by ATHOC Board of Directors members and HNSF representatives.

Competition Manager Basketball - Belongs to the division of sport and reports to the General Manager Sport.

Activities - Responsibilities: a) responsible for the organization of the competitive part of the sport, b) collects the technical rules and specifications of the sport, c) records the needs, plans, and develops, in cooperation with the supervisors, the training schedule for the sport before and during the Games, d) cooperates with the official representatives/technical commissions of the IF of the sport and the national counterparts, e) plans and organizes the test events of the sport under the supervision and control of supervisors, in collaboration with the National and the IF, f) contributes to the planning and delivery of the Paralympic Games, g) selects, trains, coordinates, and directs all staff in competition and training venues of the sport, $h$ ) collaborates with the National Federation for the selection of their technical liaison (with ATHOC), i) supervises the information material of the sport, j) proposes possible modifications to the existing, as well as to the new competition venues, according to the rules and regulations of the IF, and $\mathrm{k}$ ) in cooperation with the IF identifies the needs in human resources necessary for the competition/training sessions of the sport.

Education - Experience: a) higher or tertiary education, b) excellent knowledge of the English language (knowledge of other languages desirable), c) knowledge of how to use computer and office automation systems will be evaluated positively, d) knowledge of new technologies used in the sport, e) excellent knowledge of the sport's rules, and f) previous experience in the organization of high level events of the sport.

Figure 1. Public announcement of the Competition Manager Basketball position. 
Difficulties in recruitment of competent people were encountered only with regard to the sports not so popular in Greece (i.e., baseball), but they were adequately addressed through the support of experienced professionals from abroad and the intense/continuous training they provided to ATHOC people responsible for those sports.

The competency of ATHOC executives staff/ procedures/games command structure and all other organizational and operational parameters was quite enhanced by the test events organized in a simulated Games time set-up, in their respective venues, in a 12-month period prior to the actual Games (ATHOC, 2005a, p. 511).

Moreover, approximately 3 months before the Games, a 1-week simulation exercise, involving all key managers of the Games at the central and venue level administration, was conducted. Since the entire Games can be really organized only once, a number of possible Games time scenarios were tested in simulated real conditions and challenges. ATHOC executives participating in the Games’ Main Operations Center, as well a number of staff involved in the decision-making process of the Games, were asked on a daily basis to resolve a number of issues, communicate their decisions, and run the Games as if they were actually happening. This exercise tested all aspects of the organization and increased readiness to deal with the "real thing."

\section{Conclusion}

The infrastructure and services provided in an OG are designed to create an optimal environment for participating athletes to pursue their best possible performance. This requires organizations that operate effectively and efficiently. For Weber (1947) a bureaucracy is "superior to any other formin precision, in stability, in the stringency of its discipline and its reliability; thus it makes possible a high degree of calculability of results for the heads of organization and for those acting in relation to it" (p. 334). According to Olsen (2006), "Weber emphasized the technical superiority and the procedural rationality of bureaucracy, in contrast to the assertion that bureaucratic organization is undesirable and should be replaced by competitive markets or cooperative, power-sharing (interorganizational) networks” (p. 5). Morgan (1997) criticized Weber's theory saying that "it routinizes and mechanizes almost every aspect of human life, eroding the human spirit and capacity for spontaneous action” (p. 17), but the only way an organization like the OCOG can deliver a gigantic event like the OG on time and on budget, adhering to constant principles determined by the Olympic Charter (2014) and the HCC, is by simplifying the organizational efforts as much as possible. The results of this case study support the argument that OCOGs are bureaucratic organizations that implement IOC policy and procedures guided by Weber's (1947) five tenets of bureaucracy.

\section{References}

Al-Habil, W. I. (2011). Rationality and irrationality of Max Weber's bureaucracies. International Journal of Marketing \& Business Studies, 1(4), 106-110.

Ashforth, B. E., \& Vaidyanath, D. (2002). Work organizations as secular religions. Journal of Management Inquiry, 11(4), 359-370.

Asimakopoulos, M. (2006, September 8). Mega events organization: The role of and the impact on sports management. Keynote presentation, EASM Congress, Nicosia, Cyprus.

Athens 2004 Organizing Committee of Olympic Games. (2005a). Official Report of the XXVIII Olympiad. Vol. 1. Homecoming of the Games-Organization and operation. Athens: Author.

Athens 2004 Organizing Committee of Olympic Games. (2005b). Official Report of the XXVIII Olympiad. Vol. 2. The Games. Athens: Author.

Chelladurai, P. (2014). Managing organizations for sport and physical activity (4th ed.). Scottsdale, AZ: Holcomb Hathaway Publishers.

Flyvbjerg, B. (2006). Five misunderstandings about casestudy research. Qualitative Inquiry, 12(2), 219-245.

Frisby, D. (1985). Fragments of modernity: Theories of modernity in the work of Simmel, Kracauer and Benjamin. Cambridge, MA: The MIT Press.

Gargalianos, D., Stotlar, D., \& Toohey, K. (2012). Olympic Games complexity model. Pre-Olympic Conference, ICSEMIS, Glasgow, Scotland, July 19-24, FC118.1.

Gillham, B. (2000). Case study research methods. London: Bloomsbury Publishing.

Graetz, F., \& Smith, A. (2006). Critical perspectives on the evolution of new forms of organizing. International Journal of Strategic Change Management, 1(1/2), 127-142.

Greek Government Gazette. (1998). 66/A/24.03.1998, Law 2598/1998, article 2.

Greek Government Gazette. (2000). 676/B/31.05.2000, Decision Y228/31.05.2000 of the Prime Minister.

Hummel, R. (2007). The bureaucratic experience: The postmodern challenge (5th ed.). New York: M. E. Sharpe, Inc.

International Olympic Committee. (2014). Olympic Charter. Retrieve September 15, 2014, from www.olympic.org/ Documents/olympic_charter_en.pdf 
Jupp, V. (2006). Documents and critical research. In R. Sapford \& V. Jupp (Eds.), Data collection and analysis (2nd ed.). Thousand Oaks, CA: Sage Publications.

Kikulis, L. M., Slack, T., Hinings, B., \& Zimmermann, A. (1989). A structural taxonomy of amateur sport organizations. Journal of Sport Management, 3, 129-150.

Mintzberg, H. (1979). The structuring of organizations: A synthesis of the research. University of Illinois at UrbanaChampaign, Academy for Entrepreneurial Leadership Historical Research Reference in Entrepreneurship. Retrieved from http://ssrn.com/abstract=1496182

Morgan, G. (1997). Images of organization. Thousand Oaks, CA: Sage Publications.

Olsen, J. P. (2006). Maybe it is time to rediscover bureaucracy. Journal of Public Administration Research \& Theory, 16(1), 1-24.

Papadimitriou, D. (1994). The organizational effectiveness of Greek national sports organizations: An empirical application of the multiple constituency approach. Doctoral dissertation, Sheffield University.

Papadimitriou, D. (2002). Amateur structures and their effect on performance: The case of Greek voluntary sports clubs. Managing Leisure, 7(4), 205-219.

Punch, K. F. (1998). Introduction to social research: Quantitative and qualitative approaches. London: Sage Publications.

Punch, K. F. (2005). Introduction to social research: Quantitative and qualitative approaches. London: Sage Publications.

Slack, T. (1985). The bureaucratization of a voluntary sport organization. International Review for the Sociology of Sport, 20(3), 145-166.

Slack, T., \& Hinings, B. (1994). Institutional pressures and isomorphic change: An empirical test. Organization Studies, 15(6), 803-827.
Stemler, S. (2001). An overview of content analysis. Practical Assessment, Research \& Evaluation, 7(17). Retrieved July 31, 2014, from http://PAREonline.net/ getvn.asp?v=7\&n=17

Taylor, F. (1919). The principles of scientific management. New York \& London: Harper \& Brothers.

Theodoraki, E. (1996). An organizational analysis of the national governing bodies of sport in Britain: Organizational structures and contexts, management processes and concepts and perceptions of effectiveness. Doctoral dissertation, Loughborough University.

Theodoraki, E., \& Henry, I. (1993). Organizational structures and management processes in the national governing bodies of sport in England. Paper presented in the 3rd International Conference, Leisure Studies Association, Loughborough University.

Thibault, L., Slack, T., \& Hinings, C. R. (1991). Professionalism, structures and systems: The impact of professional staff on voluntary sport organizations. International Review for the Sociology of Sport, 26, 83-99.

Tomlinson, A., \& Young, C. (2010). Sport in history: Challenging the communis opinio. Journal of Sport History, 37(1), 5-17.

Toohey, K., \& Veal, A. J. (2007). The Olympic Games: A social science perspective. Oxon, UK: CABI.

Walonick, D. (I993). Organizational theory and behavior. Unpublished paper. Retrieved from http://www.statpac. org/walonick/organizational-theory.htm

Weber, M. (1947). The theory of social and economic organizations (A. M. Henderson \& T. Parsons, Trans.). New York: Oxford University Press.

Yin, R. K. (2014). Case study research: Design and methods. Thousand Oaks, CA: Sage Publications. 